Original

\title{
Rapid Screening for Chemopreventive Agents in Herbal Extracts in a PhIP Rat Model with DNA Adduct and Cell Proliferation as End-Points
}

\author{
Akiyoshi Nishikawa ${ }^{1}$, Takayoshi Imazawa ${ }^{1, \#}$, Takashi Umemura ${ }^{1}$, \\ Yoshihiro Yoshimura ${ }^{2}$, and Masao Hirose ${ }^{1}$ \\ ${ }^{1}$ Division of Pathology, National Institute of Health Sciences, 1-18-1 Kamiyoga, Setagaya-ku, Tokyo 158-8501, Japan \\ 2 Department of Analytical Chemistry, Hoshi University, 2-4-41 Ebara, Shinagawa-ku, Tokyo 142-8501, Japan \\ \# Present address: Toxicogenomics Project, National Institute of Biomedical Innovation, 7-6-8 Saito-Asagi, Ibaraki-city, \\ Osaka 567-0085, Japan
}

\begin{abstract}
This study was designed to rapidly screen for chemopreventive effects of three natural products, cyanidine3-glycoside, acetoside and rosemaric acid, against 2-amino-1-methyl-6-phenyl-imidazo[4,5-b]pyridine (PhIP)-induced colonic, pancreatic and prostatic carcinogenesis in rats, using DNA adduct and cell proliferation as end-points. Tenweek-old F344 male rats were maintained for 2 weeks on a powdered basal diet containing $0.03 \% \mathrm{PhIP}$ alone, PhIP together with $1 \%$ or $5 \%$ cyanidine-3-glycoside, acetoside or rosemaric acid, $1 \%$ or $5 \%$ cyanidine-3-glycoside, acetoside or rosemaric acid alone or basal diet. Immunohistochemically, PhIP DNA adduct-positive cells as well as BrdU-positive cells induced by PhIP treatment were significantly $(P<0.05)$ reduced by the combined treatment with $5 \%$ cyanidine-3glycoside in the proximal colon and pancreatic acinar cells as compared to the PhIP alone group values. In addition, combined treatment with 5\% cyanidine-3-glycoside significantly $(P<0.05)$ decreased numbers of BrdU-positive cells in the ventral prostate. Combined treatment with $5 \%$ rosemaric acid also significantly $(P<0.05)$ reduced PhIP DNA adductpositive cells in the proximal and distal colon, and ventral prostate as well as BrdU-positive cells in the lateral prostate and exocrine pancreas at $5 \%$, and in the distal colon with $1 \%$ or $5 \%$. However, co-treatment with acetoside did not significantly affect these parameters under the present experimental conditions. These results suggest that cyanidine-3glycoside and rosemaric acid may have the potential to prevent PhIP-induced carcinogenesis in the colon, prostate and/ or pancreas. (J Toxicol Pathol 2007; 20: 49-54)
\end{abstract}

Key words: herb extract, cancer chemoprevention, PhIP, DNA adduct, cell proliferation, rat

\section{Introduction}

It has been reported that dietary factors are closely associated with risk of cancer development in humans. However, both carcinogenic and anti-carcinogenic constituents may be included in food, and a positive balance in favor of protective agents is one important strategy of cancer prevention. Heterocyclic amines (HCAs) are naturally occurring carcinogenic compounds produced during broiling of meat and fish, and they are strongly mutagenic in vitro and carcinogenic in vivo ${ }^{1-3}$. Among the various HCAs tested, 2-amino-1-methyl-6-phenylimidazo[4,5-b]pyridine (PhIP) is most abundant in our

Received: 18 October 2006, Accepted: 10 December 2006 Mailing address: Akiyoshi Nishikawa, Division of Pathology, National Institute of Health Sciences, 1-18-1 Kamiyoga, Setagaya-ku, Tokyo 158-8501, Japan

TEL: 81-3-3700-9819 FAX: 81-3-3700-1425

E-mail: nishikaw@nihs.go.jp environment, and its documented induction of tumors in several organs such as the colon, mammary gland, prostate and pancreas of rodents in association with DNA adduct formation suggests its potential as a human carcinogen ${ }^{4,5}$. It is likely that lowering the carcinogenicity of HCAs including PhIP may make an important contribution to cancer chemoprevention. This might be achieved by dietary intake of compounds like polyphenols including flavonoids which are found in plants and fruits. Examples such as green tea catechins have in fact already been shown to inhibit initiation and/or post-initiation phases of carcinogenesis ${ }^{6,7}$. Interest has therefore been concentrated on the identification of potential chemopreventive agents. For this purpose, appropriate animal models and end-point parameters are clearly important.

It is now possible to detect PhIP-DNA adducts on paraffin-embedded tissue preparations using specific antibodies and immunohistochemistry ${ }^{8}$ so it has become a promising biomarker of modification of carcinogenesis. Another promising biomarker is cell proliferation, for 
Table 1. Data for Body Weights, Food Consumption and Intake of PhIP, Cyanidine-3-glucoside, Acetoside and Rosemaric Acid

\begin{tabular}{|c|c|c|c|c|c|c|}
\hline \multirow[t]{2}{*}{ Group } & \multirow{2}{*}{$\begin{array}{l}\text { Body weight } \\
\text { (g) }\end{array}$} & \multirow{2}{*}{$\begin{array}{l}\text { Food consumption } \\
\text { (g/rat/day) }\end{array}$} & \multicolumn{2}{|c|}{ Daily intake (mg/rat) } & \multicolumn{2}{|c|}{ Total Intake } \\
\hline & & & PhIP & Test chemical & $\mathrm{PhIP}$ (mg/rat) & Test chemical ( $\mathrm{g} / \mathrm{rat})$ \\
\hline None & $266.5 \pm 7.3^{\mathrm{a}}$ & 15.9 & - & - & - & - \\
\hline $\mathrm{Cy}(\mathrm{L})$ & $263.2 \pm 12.9$ & 15.8 & - & 158 & - & 2.2 \\
\hline Сy $(\mathrm{H})$ & $259.5 \pm 10.3$ & 15.6 & - & 778 & - & 10.9 \\
\hline Ac (L) & $263.2 \pm 9.9$ & 15.4 & - & 154 & - & 2.2 \\
\hline $\operatorname{Ac}(\mathrm{H})$ & $266.6 \pm 12.5$ & 15.9 & - & 759 & - & 11.1 \\
\hline Ro (L) & $268.8 \pm 8.3$ & 14.9 & - & 147 & - & 2.1 \\
\hline Ro $(\mathrm{H})$ & $266.9 \pm 12.4$ & 15.0 & - & 751 & - & 10.5 \\
\hline PhIP & $247.7 \pm 8.5^{*}$ & 14.1 & 4.2 & - & 89.3 & - \\
\hline $\mathrm{PhIP}+\mathrm{Cy}(\mathrm{L})$ & $244.1 \pm 6.7^{*}$ & 14.2 & 4.3 & 142 & 59.8 & 2.0 \\
\hline $\mathrm{PhIP}+\mathrm{Cy}(\mathrm{H})$ & $253.0 \pm 16.4^{*}$ & 14.8 & 4.5 & 742 & 62.3 & 10.4 \\
\hline $\mathrm{PhIP}+\mathrm{Ac}(\mathrm{L})$ & $244.8 \pm 3.9^{*}$ & 14.8 & 4.4 & 146 & 61.3 & 2.0 \\
\hline $\mathrm{PhIP}+\mathrm{Ac}(\mathrm{H})$ & $250.0 \pm 9.2^{*}$ & 14.9 & 4.5 & 749 & 62.9 & 10.5 \\
\hline PhIP + Ro (L) & $255.4 \pm 6.5^{*}$ & 15.2 & 4.6 & 153 & 64.1 & 2.1 \\
\hline $\mathrm{PhIP}+\mathrm{Ro}(\mathrm{H})$ & $246.3 \pm 9.7^{*}$ & 14.6 & 4.4 & 730 & 61.3 & 10.2 \\
\hline
\end{tabular}

a: Mean \pm SD.

Cy: cyanidine-3-glucoside, Ac: acetoside, Ro: rosemaric acid, L: 1\%, H: 5\%.

$* P<0.05$ vs. the respective PhIP-untreated groups.

example similarly assessed with antibodies against bromodeoxyuridine (BrdU). However, there has been no report on cancer chemoprevention using these 2 parameters as end-points except for an article regarding PhIP-induced mammary carcinogenesis ${ }^{9}$. In the present study, cyanidine3 -glycoside, an anthocyanin from tart cherry ${ }^{10}$, acetoside, a phenylpropanoid glycoside from Pedicularis or Ballota nigra $^{11,12}$ and rosemaric acid extracted from leaves of rosemary ${ }^{13}$, chemicals widely distributed in plants and exerting antioxidant properties, were examined in terms of chemopreventive effects on PhIP-induced carcinogenesis, using DNA adduct formation and cell proliferation.

\section{Materials and Methods}

\section{Animals and chemicals}

Male 8-week-old F344/DuCrj rats were obtained from Charles River Inc. (Atsugi, Japan) and housed, 3 per polycarbonate cage, in an air-conditioned room maintained at $24 \pm 2{ }^{\circ} \mathrm{C}$ and $55 \pm 5 \%$ relative humidity under a daily cycle of alternating 12-hour periods of light and darkness. The animals were given commercial standard diet (CRF-1: Oriental Yeast Inc., Tokyo, Japan) and tap water ad libitum. PhIP was purchased form Toronto Research Chemicals Inc. (Ontario, Canada) and cyanidine-3-glycoside, acetoside and rosemaric acid were generously provided by San-eigen FFI Co. (Osaka, Japan). Bromodeoxyuridine (BrdU) was purchased from Sigma Chemical Co. (St. Louis, MO, USA).

\section{Experimental design}

The protocol for this study was approved by the Animal Care and Utilization Committee of the National Institute of Health Sciences. After a 2-week acclimatization period, eighty four 10-week-old rats were divided into 14 groups each consisting of 6 animals. Rats in group 1 received no supplement and rats in groups $2-7$ received a diet supplemented with cyanidine-3-glycoside, acetoside or rosemaric acid at doses of $1 \%$ or $5 \%$ for 2 weeks. Rats in groups $8-14$ were fed for 2 weeks on a diet containing $0.03 \%$ $\mathrm{PhIP}$, and rats in groups 9-14 received additional diet supplements of cyanidine-3-glycoside, acetoside or rosemaric acid at doses of $1 \%$ or $5 \%$. The high dose, $5 \%$, was selected as the maximal dose which would not affect animal nutrition. Clinical signs were daily observed. In order to assess cell proliferative activity, rats were intraperitoneally injected with BrdU $2 \mathrm{hr}$ before sacrifice. All rats were sacrificed under ether anesthesia by exsanguination from the abdominal aorta. At autopsy, colons, pancreata and prostates were removed and fixed in cold acetone. These organs were routinely processed, embedded in paraffin, cut at $4 \mu \mathrm{m}$ and stained with hematoxylin and eosin (H-E). Immunohisochemistry for BrdU and PhIP-DNA adducts was carried out using antiBrdU antibodies (Dako Japan Co. Ltd., Kyoto, Japan) and anti-PhIP-DNA antibodies, a generous gift from Prof. T. Shirai, Nagoya City University Medical School. In both proximal and distal portions of the colon, more than 1000 mucosal epithelial cells were counted for positive reactions of BrdU and DNA adducts under a light microscope at a magnification of $\times 400$. Similarly, prostate gland epithelial cells were counted in the ventral, dorsal and lateral lobes along with acinar cells of the pancreas.

\section{Statistical evaluation}

Data for body weights, DNA adducts and BrdUlabeling indices were examined using Bartlett's test for homogeneity of variance between groups. If no significant heterogeneity was detected, analysis of variance (ANOVA) was applied. If significant heterogeneity of variance was detected, the Kruskal-Wallis test was conducted. When 

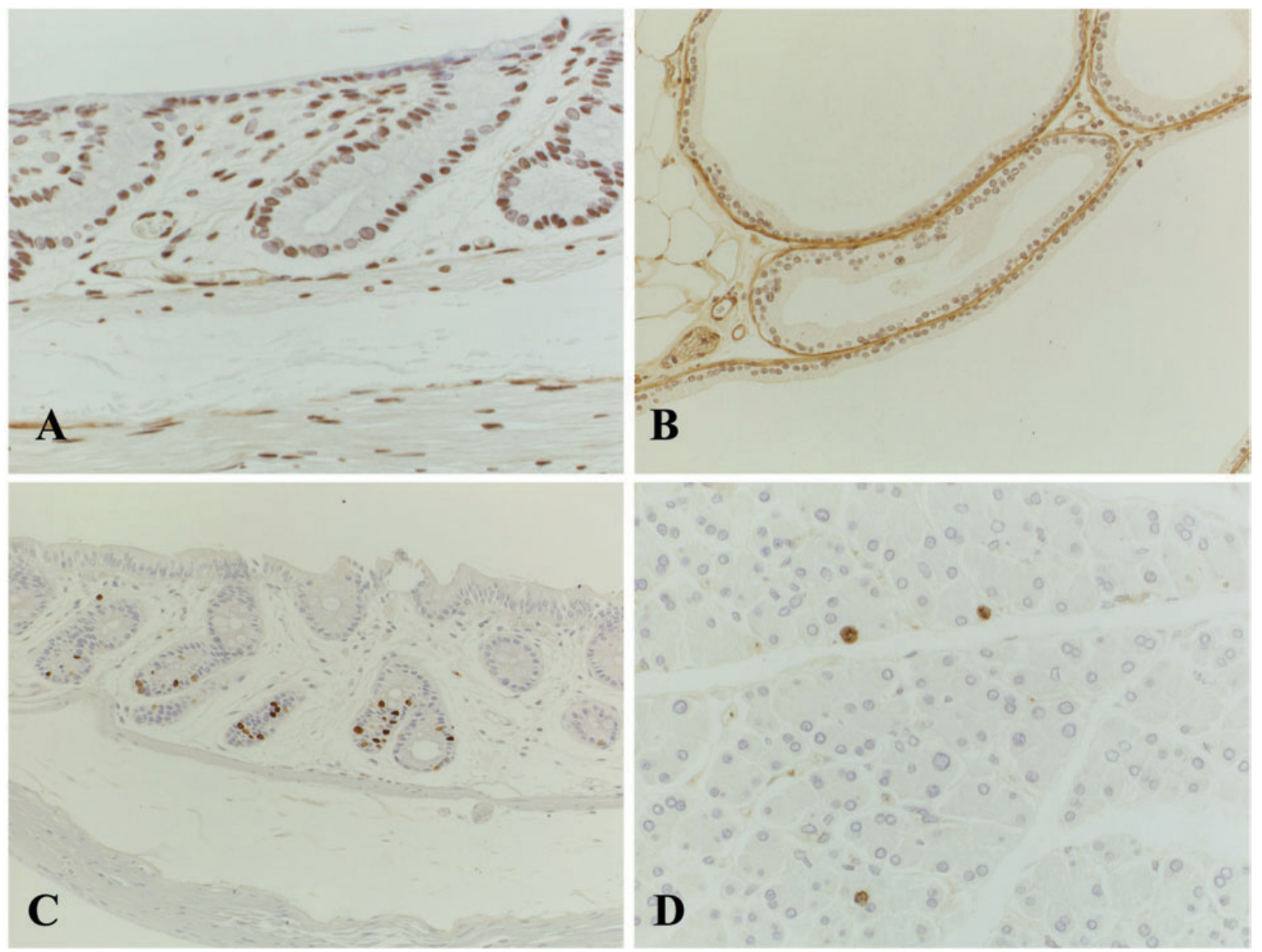

Fig. 1. Immunohistochemistry for PhIP-DNA adduct formation in the distal colon (A) and ventral prostate (B) of rats treated with PhIP alone. Immunohistochemistry for BrdU in the distal colon $(\mathbf{C})$ and pancreas $(\mathbf{D})$ of rats treated with PhIP alone.

parameters were found to demonstrate significant differences between groups, Dunnett's multiple comparison test was applied to evaluate the statistical significance between pairs of groups.

\section{Results}

\section{Body weight and food consumption (Table 1)}

Except in the 5\% cyanidine-3-glycoside-treated group, the final body weights were significantly $(P<0.05)$ reduced in the groups receiving PhIP as compared to the respective groups without PhIP exposure. However, among the groups with PhIP exposure or those without the exposure, the final body weights were comparable, suggesting no or little toxicity of cyanidine-3-glycoside, acetoside and rosemaric acid administered in the present experiment. Food consumption was comparable between groups, and chemical intakes were dose-related.

\section{DNA adduct formation (Fig. 1 and Table 2)}

The percentages of cells positive for PhIP-DNA adduct were significantly $(P<0.05)$ decreased in the proximal colon $(25.8 \%)$ and exocrine pancreas $(20.9 \%)$ of the group cotreated with $5 \%$ cyanidine-3-glycoside as compared to the $\mathrm{PhIP}$ alone group (34.2\% and $26.8 \%$, respectively). The PhIP-DNA adduct-positive ratios in these organs were also reduced by the $1 \%$ cyanidine- 3 -glycoside treatment, albeit without statistical significance. The co-treatment with 5\% acetoside only showed a tendency for dose-dependent decrease in the PhIP-DNA adduct-positive ratios in the exocrine pancreas, but there was little evidence of effects of acetoside on the colon and prostate. The PhIP-DNA adductpositive ratios were reduced in a dose-dependent manner in the organs of the rosemaric acid-treated groups, except for the dorsal prostate. There were significant differences $(P<0.05)$ in the proximal $(24.6 \%)$ and distal $(20.1 \%)$ colon, and ventral prostate $(35.0 \%)$ at the high dose as compared to the respective PhIP alone group values (34.2\%, 26.9\% and $43.6 \%)$.

\section{Cell proliferation activity (Fig. 1 and Table 3)}

Among the PhIP-untreated groups, BrdU-labeling 
Table 2. Effects of Cyanidine-3-glucoside, Acetoside and Rosemaric Acid on PhIP-DNA Adduct Formation in Various Organ Sites of Male F344 Rats

\begin{tabular}{|c|c|c|c|c|c|c|c|}
\hline \multirow{2}{*}{ Organ } & \multicolumn{7}{|c|}{ PhIP DNA adduct-positive cells (\%) } \\
\hline & $\mathrm{PhIP}$ & $\mathrm{PhIP}+\mathrm{Cy}(\mathrm{L})$ & $\mathrm{PhIP}+\mathrm{Cy}(\mathrm{H})$ & $\mathrm{PhIP}+\mathrm{Ac}(\mathrm{L})$ & $\mathrm{PhIP}+\mathrm{Ac}(\mathrm{H})$ & $\mathrm{PhIP}+\mathrm{Ro}(\mathrm{L})$ & $\mathrm{PhIP}+\mathrm{Ro}(\mathrm{H})$ \\
\hline Proximal colon & $34.2 \pm 6.3^{\mathrm{a}}$ & $31.4 \pm 5.3$ & $25.8 \pm 5.6^{*}$ & $35.1 \pm 7.1$ & $32.6 \pm 5.4$ & $29.8 \pm 6.0$ & $24.6 \pm 4.7 *$ \\
\hline Distal colon & $26.9 \pm 5.8$ & $25.8 \pm 5.5$ & $22.6 \pm 6.4$ & $26.5 \pm 4.9$ & $27.7 \pm 5.2$ & $23.4 \pm 4.9$ & $20.1 \pm 3.5^{*}$ \\
\hline Ventral prostate & $43.6 \pm 7.4$ & $42.4 \pm 8.3$ & $36.3 \pm 6.3$ & $45.2 \pm 6.5$ & $41.2 \pm 6.4$ & $39.5 \pm 4.8$ & $35.0 \pm 5.1 *$ \\
\hline Dorsal prostate & $27.4 \pm 4.1$ & $28.6 \pm 5.4$ & $25.7 \pm 4.3$ & $27.4 \pm 4.4$ & $28.9 \pm 5.5$ & $27.6 \pm 4.5$ & $25.8 \pm 5.8$ \\
\hline Lateral prostate & $25.5 \pm 5.6$ & $26.3 \pm 5.2$ & $23.4 \pm 5.5$ & $24.1 \pm 4.7$ & $27.8 \pm 5.0$ & $23.7 \pm 4.1$ & $22.2 \pm 4.8$ \\
\hline Exocrine pancreas & $26.8 \pm 5.1$ & $24.1 \pm 5.9$ & $20.9 \pm 4.1 *$ & $25.1 \pm 4.8$ & $24.2 \pm 5.0$ & $23.1 \pm 3.3$ & $21.1 \pm 6.5$ \\
\hline
\end{tabular}

a: Mean \pm SD.

Cy: cyanidine-3-glucoside, Ac: acetoside, Ro: rosemaric acid, L: 1\%, H: 5\%.

*: $P<0.05$ vs. the PhIP alone group.

Table 3. Effects of Cyanidine-3-glucoside, Acetoside and Rosemaric Acid on Cell Proliferation Increased by PhIP in Various Organ Sites of Male F344 Rats

\begin{tabular}{|c|c|c|c|c|c|c|c|}
\hline \multirow{2}{*}{ Organ } & \multicolumn{7}{|c|}{ BrdU-labeling index $(\%)$} \\
\hline & None & $\mathrm{Cy}(\mathrm{L})$ & $\mathrm{Cy}(\mathrm{H})$ & $\operatorname{Ac}(\mathrm{L})$ & $\operatorname{Ac}(\mathrm{H})$ & $\operatorname{Ro}(\mathrm{L})$ & $\operatorname{Ro}(\mathrm{H})$ \\
\hline Proximal colon & $6.93 \pm 0.35^{\mathrm{a}}$ & $7.09 \pm 0.50$ & $6.69 \pm 0.57$ & $6.99 \pm 0.22$ & $6.63 \pm 0.50$ & $6.57 \pm 0.48$ & $6.83 \pm 0.30$ \\
\hline Distal colon & $6.52 \pm 0.25$ & $6.59 \pm 0.37$ & $6.47 \pm 0.63$ & $6.88 \pm 0.70$ & $6.58 \pm 0.47$ & $6.47 \pm 0.31$ & $6.75 \pm 0.28$ \\
\hline Ventral prostate & $0.17 \pm 0.03$ & $0.18 \pm 0.03$ & $0.18 \pm 0.04$ & $0.17 \pm 0.04$ & $0.17 \pm 0.05$ & $0.16 \pm 0.03$ & $0.18 \pm 0.04$ \\
\hline Dorsral prostate & $0.18 \pm 0.04$ & $0.17 \pm 0.03$ & $0.18 \pm 0.02$ & $0.18 \pm 0.03$ & $0.17 \pm 0.03$ & $0.18 \pm 0.04$ & $0.19 \pm 0.03$ \\
\hline Lateral prostate & $0.18 \pm 0.02$ & $0.17 \pm 0.03$ & $0.19 \pm 0.04$ & $0.18 \pm 0.03$ & $0.19 \pm 0.03$ & $0.18 \pm 0.03$ & $0.18 \pm 0.03$ \\
\hline \multirow[t]{2}{*}{ Exocrine pancreas } & $0.15 \pm 0.03$ & $0.16 \pm 0.04$ & $0.16 \pm 0.03$ & $0.14 \pm 0.04$ & $0.15 \pm 0.05$ & $0.16 \pm 0.03$ & $0.15 \pm 0.03$ \\
\hline & $\mathrm{PhIP}$ & $\mathrm{PhIP}+\mathrm{Cy}(\mathrm{L})$ & $\mathrm{PhIP}+\mathrm{Cy}(\mathrm{H})$ & $\mathrm{PhIP}+\mathrm{Ac}(\mathrm{L})$ & $\mathrm{PhIP}+\mathrm{Ac}(\mathrm{H})$ & $\mathrm{PhIP}+\mathrm{Ro}(\mathrm{L})$ & $\mathrm{PhIP}+\mathrm{Ro}(\mathrm{H})$ \\
\hline Proximal colon & $8.12 \pm 0.70^{\#}$ & $8.28 \pm 0.53$ & $7.35 \pm 0.46^{*}$ & $8.36 \pm 0.58$ & $8.19 \pm 1.06$ & $7.79 \pm 0.89$ & $7.39 \pm 0.90$ \\
\hline Distal colon & $7.58 \pm 0.89^{\#}$ & $6.93 \pm 0.67$ & $6.82 \pm 0.34$ & $7.94 \pm 0.83$ & $7.17 \pm 0.80$ & $6.55 \pm 0.40^{*}$ & $6.49 \pm 0.59 *$ \\
\hline Ventral prostate & $0.25 \pm 0.04^{\#}$ & $0.23 \pm 0.04$ & $0.19 \pm 0.03 *$ & $0.24 \pm 0.03$ & $0.25 \pm 0.03$ & $0.23 \pm 0.04$ & $0.20 \pm 0.04$ \\
\hline Dorsal prostate & $0.23 \pm 0.03$ & $0.21 \pm 0.06$ & $0.20 \pm 0.05$ & $0.21 \pm 0.03$ & $0.22 \pm 0.04$ & $0.20 \pm 0.04$ & $0.21 \pm 0.03$ \\
\hline Lateral prostate & $0.25 \pm 0.05^{\#}$ & $0.24 \pm 0.05$ & $0.20 \pm 0.04$ & $0.23 \pm 0.05$ & $0.21 \pm 0.04$ & $0.21 \pm 0.04$ & $0.19 \pm 0.02 *$ \\
\hline Exocrine pancreas & $0.24 \pm 0.04^{\#}$ & $0.23 \pm 0.04$ & $0.18 \pm 0.03^{*}$ & $0.24 \pm 0.03$ & $0.22 \pm 0.05$ & $0.20 \pm 0.03$ & $0.19 \pm 0.04 *$ \\
\hline
\end{tabular}

a Mean $\pm \mathrm{SD}$.

Cy: cyanidine-3-glucoside, Ac: acetoside, Ro: rosemaric acid, L: 1\%, H: 5\%.

*: $P<0.05$ vs. the PhIP alone group.

$\#: P<0.05$ vs. the untreated control group.

indices were comparable. BrdU-labeling indices were significantly $(P<0.05)$ increased in the proximal $(8.12 \%)$ and distal $(7.58 \%)$ colons, ventral $(0.25 \%)$ and lateral $(0.25 \%)$ prostates, and exocrine pancreas $(0.24 \%)$ in the PhIP alone group as compared to the non-treatment group values (6.93, $6.52,0.17,0.18$, and $0.15 \%)$. BrdU-labeling indices in the dorsal prostate of the PhIP alone group also showed a tendency to increase albeit without statistical significance. Co-treatment of 5\% cyanidine-3-glycoside with PhIP significantly $(P<0.05)$ reduced the BrdU-labeling indices in the proximal colon $(7.35 \%)$, ventral prostate $(0.19 \%)$ and exocrine pancreas $(0.18 \%)$ as compared to the PhIP alone group values. Co-treatments with $1 \%$ and $5 \%$ acetoside did not appear to influence the BrdU-labeling indices in any of the organs examined. With $1 \%$ and $5 \%$ rosemaric acid significant reductions $(P<0.05)$ were noted in the distal colon $(6.55 \%$ and $6.49 \%)$ as compared to the PhIP alone group value. The BrdU-labeling indices in the lateral prostate and exocrine pancreas were also dose-dependently decreased by the treatment with rosemaric acid, these being statistically $(P<0.05)$ significant in the $5 \%$ rosemaric acidtreated group.

\section{Discussion}

In the present study, it could be clearly shown by immunohistochemistry that PhIP, an HCA, induces DNA adduct formation in the colon mucosal epithelium, prostatic gland epithelium and pancreatic acini, which are known to be targets of PhIP carcinogenicity. This is consistent with previous results $^{8}$, validating our short-term assay system for evaluating the efficacy of modifying factors on carcinogenesis. In addition, cell proliferation activity assessed by immunohistochemistry for BrdU was also increased in the same target organs. It is well known that increase and decrease in numbers of cells undergoing 
division are correlated with carcinogenicity or tumor promotion and cancer preventive activity, respectively ${ }^{14-16}$. The fact that cyanidine-3-glycoside, acetoside or rosemaric acid alone did not affect cell proliferation is in line with their lack of tumor-promoting effects.

It has been shown in the Ames assay that all three of our test compounds lower the mutagenicity of PhIP (unpublished data). Therefore, they were expected to exert chemopreventive effects on PhIP-induced carcinogenesis in vivo. In fact, in the present study, the 5\% cyanidine-3glycoside-treatment significantly reduced PhIP-DNA adducts in the proximal colon and exocrine pancreas, while $5 \%$ rosemaric acid-treatment similarly suppressed adduct formation in the proximal and distal colon, as well as the ventral prostate. Because cell proliferation assessed by BrdU-labeling was similarly decreased in these organs, our results suggest that cyanidine-3-glycoside and rosemaric acid can inhibit colon, prostatic or pancreatic carcinogenesis in rats. However, the doses used in the present study were high and the possibility that higher physiological doses might be protective in humans needs to be investigated.

Although the precise mechanisms underlying the inhibition of PhIP-DNA adduct formation by these chemicals remain unclear, it is very likely that suppression of CYP1A1/2 that metabolically activates PhIP, induction of xenobiotic phase 2 enzymes responsible for detoxification and reduction in oxidative stress are involved. In addition to antioxidative action ${ }^{10}$, anthocyanins including cyanidine have been shown to exert anti-tumoral effects in vitro ${ }^{17-20}$. Recently, it was found that proanthocyanidine, a polyphenol contained in cacao, can inhibit the in vitro or ex vivo mutagenicity of $\mathrm{PhIP}^{21}$ as well as other $\mathrm{HCAs}^{22}$, conceivably by trapping electrophilic ultimate carcinogens activated metabolically. In fact, cacao liquor polyphenols were earlier found to inhibit pancreatic carcinogenesis in rats receiving $\mathrm{PhIP}^{21}$ and lung carcinogenesis in a rat multi-organ model ${ }^{23}$.

In the present study, except for a slight but dosedependent decrease of PhIP-DNA adduct formation in the pancreas, acetoside affected neither DNA adduct formation nor BrdU-labeling in the three target organs investigated. While acetoside has been reported to exert inhibitory effects on growth and proliferation of human and rat cancer cells in vitro $^{24-26}$, the present in vivo data suggest only a weak, if any, chemopreventive potential. Regarding the antioxidant rosemaric acid ${ }^{27}$, DMBA-DNA adduct formation in rat mammary glands was inhibited more than $40 \%$ and mammary carcinogenesis approximately $70 \%$ in one study ${ }^{28}$. Offord et al. ${ }^{29}$ have documented that rosemaric acid reduced benzo $(a)$ pyrene-DNA adducts in human bronchial cells (BEAS-2B) by about $80 \%$, thus providing evidence of antiinitiation activity of rosemaric acid. In addition, the activity of the xenobiotic metabolizing enzyme CYP1A1 was inhibited more than $70 \%$, in line with our present results.

In conclusion, cyanidine-3-glycoside and rosemaric acid were found to inhibit DNA adduct formation and cell proliferation in target organs of rats exposed to PhIP, suggesting they deserve consideration as new candidate chemopreventive agents against prostate, colon and/or pancreatic carcinogenesis. Long-term experiments would be necessary in order to elucidate the chemopreventive efficacy of these 2 compounds especially in terms of organ specificity.

Acknowledgement: This work was supported in part by a grant-in-aid from the Japan Food Chemical Research Foundation.

\section{References}

1. Sugimura T and Sato S. Mutagens-carcinogens in foods. Cancer Res. 43: 2415-2421. 1983.

2. Wakabayashi K, Nagao M, Esumi H, and Sugimura T. Foodderived mutagens and carcinogens. Cancer Res. 52: 20922098. 1992.

3. Felton JS and Knize MG. Occurrence, identification, and potential mutagenicity of heterocyclic amines in cooked food. Mutat Res. 259: 205-217. 1991.

4. Ito N, Hasegawa R, Sano M, Tamano S, Esumi H, Takayama $\mathrm{S}$, and Sugimura T. A new colon and mammary carcinogen in cooked food, 2-amino-1-methyl-6-phenyl-imidazo[4,5b]pyridine (PhIP). Carcinogenesis. 12: 1502-1506. 1991.

5. Shirai T, Sano M, Tamano S, Takahashi S, Hirose $M$, Futakuchi M, Hasegawa R, Imaida K, Matsumoto K, Wakabayashi K, Sugimura T, and Ito N. The prostate: a target for carcinogenicity of 2-amino-1-methyl-6-phenylimidazo[4,5- $b]$ pyridine (PhIP) derived from cooked foods. Cancer Res. 57: 195-198. 1997.

6. Hirose M, Akagi K, Hasegawa R, Yaono M, Satoh T, Hara Y, Wakabayashi K, and Ito N. Chemoprevention of 2amino-1-methyl-6-phenylimidazo[4,5-b]-pyridine (PhIP)induced mammary gland carcinogenesis by antioxidants in F344 female rats. Carcinogenesis. 16: 217-221. 1995.

7. Hirose M, Mizoguchi Y, Yaono M, Tanaka H, Yamaguchi $\mathrm{T}$, and Shirai T. Effects of green tea catechins on the progression or late promotion stage of mammary gland carcinogenesis in female Sprague-Dawley rats pretreated with 7,12-dimethylbenz( $a$ anthracene. Cancer Lett. 112: 141-147. 1997.

8. Takahashi S, Tamano S, Hirose M, Kimoto N, Ikeda Y, Sakakibara M, Tada M, Kadlubar FF, Ito N, and Shirai T. Immnohistochemical demonstration of carcinogen-DNA adducts in tissues of rats given 2-amino-1-methyl-6-phenylimidazo[4,5-b]pyridine (PhIP): detection in paraffinembedded sections and tissue distribution. Cancer Res. 58: 4307-4313. 1998.

9. Futakuchi M, Cheng JL, Hirose M, Kimoto N, Cho Y-M, Iwata T, Kasai M, Tokudome S, and Shirai T. Inhibition of conjugated fatty acids derived from safflower or perilla oil of induction and development of mammary tumors in rats induced by 2-amino-1-methyl-6-phenylimidazo[4,5b]pyridine (PhIP). Cancer Lett. 178: 131-139. 2002.

10. Wang H, Nair MG, Strasburg GM, Chang YC, Booren AM, Gray JI, and DeWitt DL. Antioxidant and antiinflammatory activities of anthocyanins and their aglycon, cyanidin, from tart cherries. J Nat Prod. 62: 294-296. 1999.

11. Li J, Wang FP, Zheng R, Liu ZM, and Jia Z. Protection of phenylpropanoid glycosides from Pedicularis against oxidative hemolysis in vitro. Planta Med. 59: 315-317. 
1993.

12. Seidel V, Verholle M, Malard Y, Tillequin F, Fruchart JC, Duriez P, Bailleul F, and Teissier E. Phenylpropanoids from Ballota nigra L. inhibit in vitro LDL peroxidation. Phytother Res. 14: 93-98. 2000.

13. Imatani R, Nakarani N, and Fuwa H. Antioxidative effect of the constituents of rosemary (Rosemarinus officinalis L.) and their derivatives. Agric Biol Chemo. 47: 521-528. 1983.

14. Ito $\mathrm{N}$, Hirose $\mathrm{M}$, and Takahashi S. Cell proliferation and forestomach carcinogenesis. Environ Health Perspect. 101 (Suppl 5): 107-110. 1993.

15. Kawamori T, Tanaka T, Ohnishi M, Hirose Y, Nakamura Y, Satoh K, Hara A, and Mori H. Chemoprevention of azoxymethane-induced colon carcinogenesis by dietary feeding of S-methyl methane thiosulfonate in male F344 rats. Cancer Res. 55: 4053-4058. 1995.

16. Hirose M, Hakoi K, Takahashi S, Hoshiya T, Akagi K, Lin C, Saito K, Kaneko H, and Shirai T. Sequential morphological and biological changes in the glandular stomach induced by oral administration of catechol to male F344 rats. Toxicol Pathol. 27: 448-455. 1999.

17. Kamei H, Kojima T, Hasegawa M, Koide T, Umeda $T$, Yukawa T, and Terabe K. Suppression of tumor cell growth by anthocyanins in vitro. Cancer Invest. 13: 590-594, 1995.

18. Koide T, Kamei H, Hashimoto Y, Kojima T, and Hasegawa M. Antitumor effect of hydrolyzed anthocyanin from grape rinds and red rice. Cancer Biother Radiopharm. 11: 273277. 1996

19. Koide T, Hashimoto Y, Kamei H, Kojima T, Hasegawa M, and Terabe K. Antitumor effect of anthocyanin fractions extracted from red soybeans and red beans in vitro and in vivo. Cancer Biother Radiopharm. 12: 277-280. 1997.

20. Kamei H, Hashimoto Y, Koide T, Kojima T, and Hasegawa M. Anti-tumor effect of methanol extracts from red and white wines. Cancer Biother Radiopharm. 13: 447-452. 1998.

21. Yamagishi $M$, Natsume $M$, Osakabe $N$, Nakamura $H$, Furukawa F, Imazawa T, Nishikawa A, and Hirose M.
Effects of cacao liquor proanthocyanidins on PhIP-induced mutagenesis in vitro, and in vivo mammary and pancreatic tumorigenesis in female Sprague-Dawley rats. Cancer Lett. 185: 123-130. 2002.

22. Yamagishi M, Natsume M, Nagaki A, Adachi T, Osakabe N, Takizawa T, Kumon H, and Osawa T. Antimutagenic activity of cacao: inhibitory effect of cacao liquor polyphenols on the mutagenic action of heterocyclic amines. J Agric Food Chem. 48: 5074-5078. 2000.

23. Yamagishi $M$, Natsume $M$, Osakabe N, Okazaki K, Furukawa F, Imazawa T, Nishikawa A, and Hirose M. Chemoprevention of lung carcinogenesis by cacao liquor proanthocyanidins in a male rat multi-organ carcinogenesis model. Cancer Lett. 191: 49-57. 2003.

24. Saracoglu I, Inoue M, Calis I, and Ogihara Y. Studies on constituents with cytotoxic and cytostatic activity of two Turkish medicinal plants Phlomis armeniaca and Scutellaria salviifolia. Biol Pharm Bull. 18: 1396-1400. 1995.

25. Li J, Zheng Y, Zhou H, Su B, and Zheng R. Differentiation of human gastric adenocarcinoma cell line MGc80-3 induced by verbascoside. Planta Med. 63: 499-502. 1997.

26. Nagao T, Abe F, and Okabe H. Antiproliferative constituents in the plants 7. Leaves of Clerodendron bungei and leaves and bark of C. trichotomum. Biol Pharm Bull. 24: 13381341. 2001.

27. Ho C-T, Wang M, Wei G-J, Huang T-C, and Huang M-T. Chemistry and antioxidative factors in rosemary and sage. Biofactors. 13: 161-166. 2000.

28. Singletary K, MacDonald C, and Wallig M. Inhibition by rosemary and carnosol of 7,12-dimetnylbenz $[a]$ anthracene (DMBA)-induced rat mammary tumorigenesis and in vivo DMBA-DNA adduct formation. Cancer Lett. 104: 43-48. 1996.

29. Offord EA, Mace K, Ruffieux C, Malnoe A, and Pfeifer AM. Rosemary components inhibit benzo $[a]$ pyrene-induced genotoxicity in human bronchial cells. Carcinogenesis. 16: 2057-2062. 1995. 